\title{
MIMO Antenna Performances on Microstrip Antenna with EBG Structure for WLAN Applications
}

\author{
Nur Nasyilla Othman ${ }^{1,}$, , Wan Noor Najwa Wan Marzudi, a, \\ Nur Faizah Mohamad Yusof ${ }^{1, ~ a, ~, ~ Z u h a i r i a h ~ Z a i n a l ~ A b i d i n ~}{ }^{1,}$, \\ Siti Zarina Mohamad Muji ${ }^{1, a}$ Ma Yue ${ }^{2, b}$ \\ ${ }^{1}$ Research Centre of Applied Electromagnetic, Universiti Tun Hussein Onn Malaysia,Johor, \\ Malaysia \\ ${ }^{2}$ National Astronomical Observatories (NAOC), Chinese Academy of Sciences, China \\ a syilla.othman@gmail.com, ${ }^{a}$ wannoornajwa@gmail.com, ${ }^{a}$ zuhairia@uthm.edu.my, \\ aszarina@uthm.edu.my, byuema@nao.cas.cn
}

Keywords: Microstrip antenna, EBG structures, MIMO performances

\begin{abstract}
A 2 elements microstrip MIMO antenna with Electromagnetic Bandgap (EBG) structures is presented. The EBG structures is employed in order to reduce the coupling between the elements. Simulated scattering parameters with and without EBG structures are compared. An evaluation of MIMO antenna characteristics is presented, with the analysis of the mutual coupling, correlation coefficients, total active reflection coefficients (TARC), capacity loss and channel capacity using Computer Simulation Technology (CST) Microwave Studio Software. It shown that, the proposed antenna is a good candidate for WLAN practical applications.
\end{abstract}

\section{Introduction}

Recently, MIMO antenna system generated great interest for researchers to improve reliability and enhanced channel capacity in wireless communication fields[1].The challenge in designing MIMO antenna is the mutual coupling between antenna elements. The mutual couplings exist due to the finite spacing between elements. Higher antenna efficiencies and lower correlation coefficients can be achieved with lower mutual coupling[2]. Previous work that related with reduction of mutual coupling techniques studied in [3-11]. Authors in[3] proposed T-Shape slot impedance transformer with isolation over $19.2 \mathrm{~dB}$ and $22.8 \mathrm{~dB}$ at $2.4-2.48 \mathrm{GHz}$ and $3.4-3.6 \mathrm{GHz}$ respectively with correlation coefficients less than 0.5 . Mutual coupling lower than $-28 \mathrm{~dB}$ over WLAN band was achieved in[4], by introducing an additional non radiating folded shorting strip between elements and ground plane. Two packed antennas with coupling element is reported in[5] with mutual coupling, $\mathrm{S}_{21}<-15 \mathrm{~dB}$ was obtained, with edge to edge separation is $0.04 \lambda$. The use of neutralization line technique proposed in[6], with minimization of mutual coupling less than $-20 \mathrm{~dB}$ was achieved. Other approaches to reduce mutual coupling and enhanced isolation of the MIMO antenna i.e. soft surface[7], slits on ground plane[8], defected ground structures (DGS)[9, 10] and metamaterial [11]. The incorporation of electromagnetic band gap (EBG) structures is an attractive idea in antenna community. This is because the electromagnetic band gap (EBG) structure has ability to reduce mutual coupling as well as increase the MIMO antenna performance[12, 13].

This paper presents a planar H-shaped antenna with EBG structure, operating at $2.45 \mathrm{GHz}$ applications. The S-parameters result for the proposed antenna with and without EBG structures are compared. In addition, the MIMO antenna performances in term of mutual coupling, correlation coefficients, total active reflection coefficients (TARC), capacity loss and channel capacity are analyzed. 


\section{Antenna Design Concept and Structure}

\section{A. Electromagnetic Bandgap (EBG) Structure}

EBG structure with high impedance surfaces are realized with periodic arrangement of metallic element. The configuration of EBG structure is illustrated in Fig 1. A center patch is connected to four folded bend metallic connecting lines. Folded bend acts as connecting bridge that plays important role in determining band gap position. The connecting bridge provides the inductance while the gap within the cell and the gap within adjacent cell provide capacitance. Thus, the characteristic result of the EBG structure similar to that in [12].

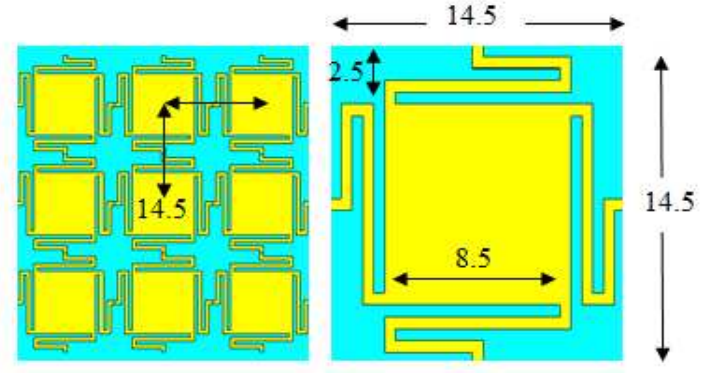

Fig 1: Configuration of EBG structure design. (a) 3x3 array EBG cell and (b) EBG unit cell (in $\mathrm{mm}$ ) [12].

\section{B. Antenna array with EBG structure}

Fig 2 shows the configuration of the proposed antenna array design with EBG structures. EBG structures is placed in between antenna elements. The integration of EBG structures in microstrip antenna array is quite attractive for their ability to suppress surface wave and reduce the mutual coupling. The purpose of EBG structure is to enhance the performance of antenna array and reduce mutual coupling between them.

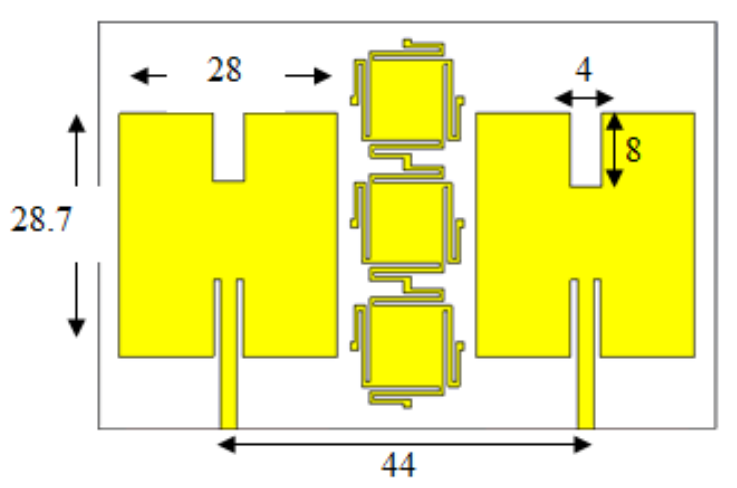

(a)

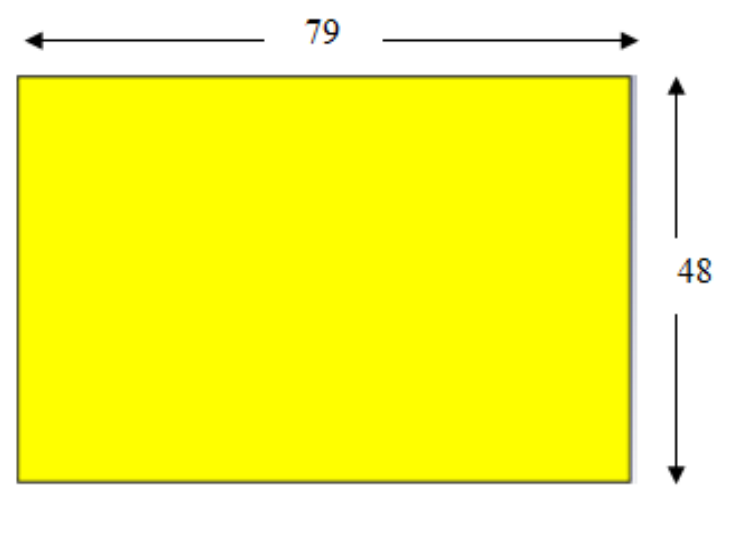

(b)

Fig 2: The configuration of the proposed antenna array design with EBG structure, (a) front view and (b) back view (in mm).

\section{Result and Discussions}

\section{A.S-parameters}

Fig 3 shows the simulated S-parameters result of the proposed antenna with and without EBG structure. It can be seen that an improved isolation of $-3 \mathrm{~dB}$ is achievable against proposed antenna without EBG structures. The mutual coupling of the proposed antenna design improved form - 16.08 $\mathrm{dB}$ to $-19.25 \mathrm{~dB}$ after the EBG structures employed between the elements. The comparison between simulated and measured results is plotted in Fig 4. 


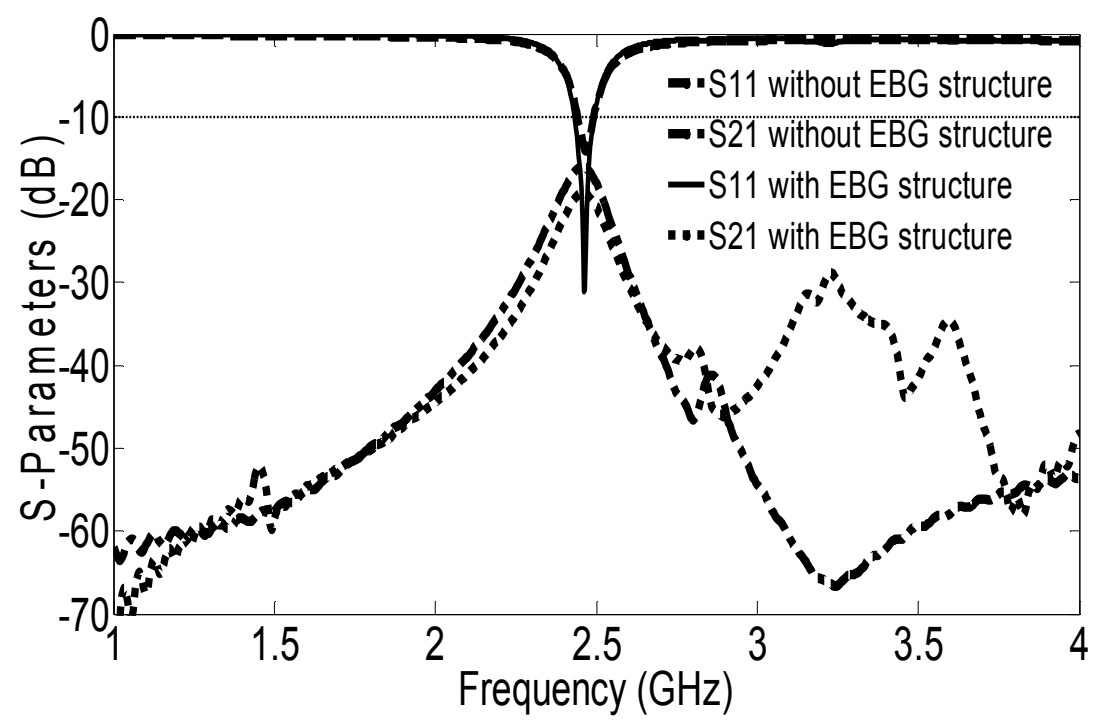

Fig 3: Comparative plot of simulated S-parameters of the proposed antenna with and without EBG structures.

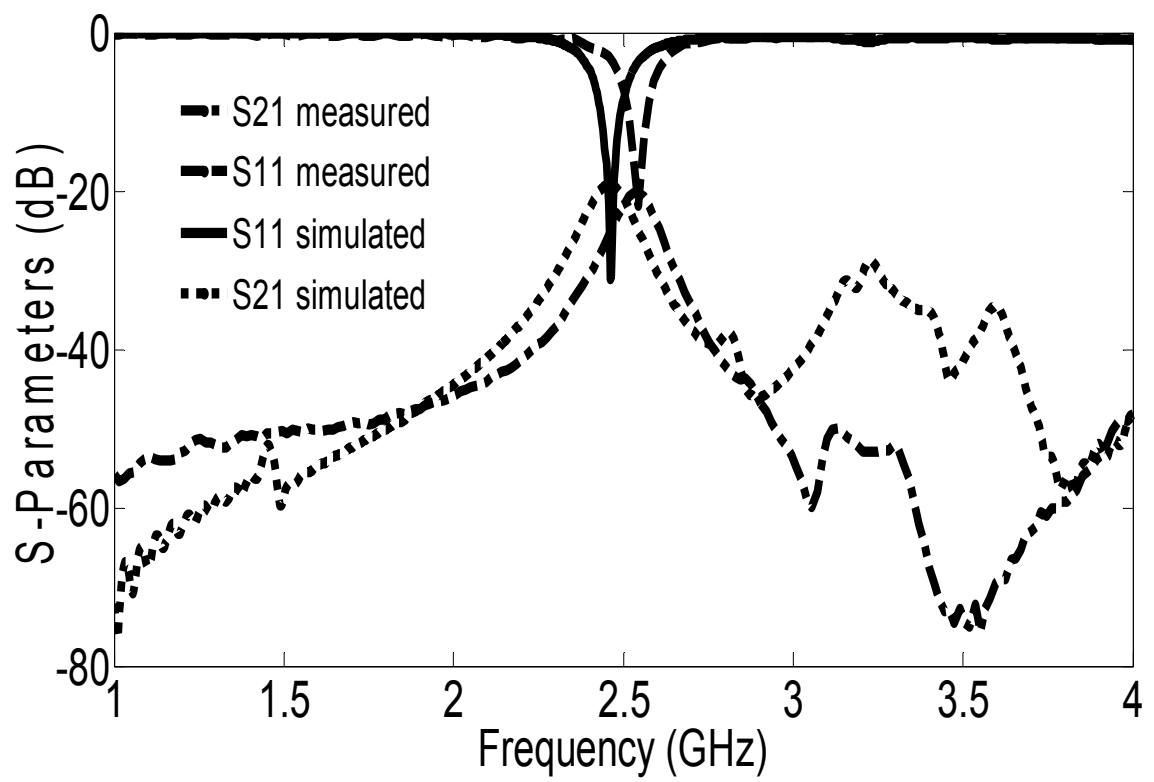

Fig 4: Comparative plot of measured S-parameters of the proposed antenna with EBG structures.

\section{B. Envelope Correlation Coefficient}

To evaluate the capabilities of the MIMO antenna, an envelope correlation coefficient is an important criterion to be presented. Envelope correlation coefficient can be computed using farfield radiation pattern and using S-parameters. In this case, envelope correlation expressed using sparameters by using following equation[14]

$$
\rho_{\mathrm{e}}=\frac{\left|\mathrm{s}^{*}{ }_{11} \mathrm{~S}_{12}+\mathrm{S}_{21}{ }_{21} \mathrm{~S}_{22}\right|^{2}}{\left({ }_{1}-\mathrm{s}_{11}\left|{ }^{2}{ }_{\mathrm{S}_{21}}\right|^{2}\right)\left({ }_{1-}-\left.\left.\mathrm{s}_{22}\right|^{2}{ }_{-} \mathrm{S}_{12}\right|^{2}\right)}
$$

An improvement of the ECC can be seen after the EBG structures was applied in Fig 5 and it fulfils the characteristic of diversity $p_{e}<0.5[8]$. Therefore, the proposed antenna is suitable candidate for WLAN applications. 


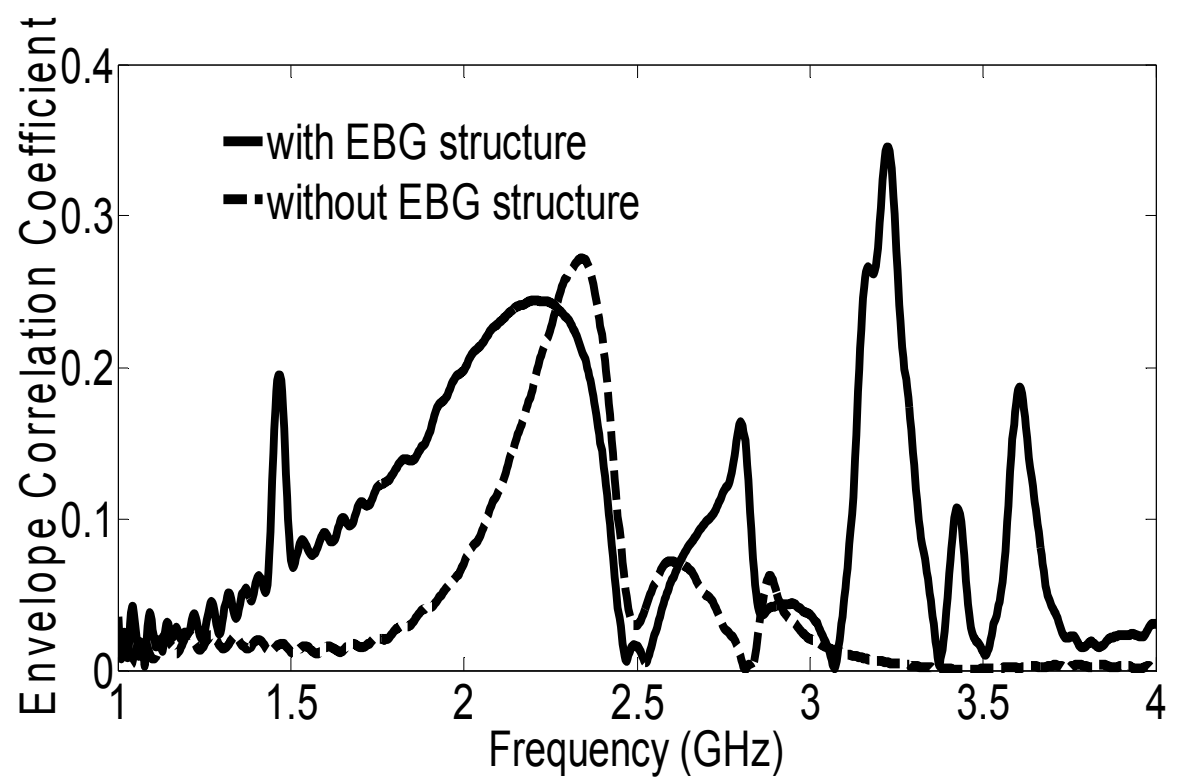

Fig 5: Simulated envelope correlation coefficient of the proposed antenna with and without EBG structure.

\section{TARC and Capacity Loss}

Table 2 represents the summarized of the MIMO performances of the antenna with and without the EBG. The results show that the antennas with EBG structures have lower loss of capacity and better performances of TARC and correlation coefficient. The channel capacity of microstrip with and without EBG structure is $5.589 \mathrm{bits} / \mathrm{s} / \mathrm{Hz}$ and $5.768 \mathrm{bits} / \mathrm{s} / \mathrm{Hz}$ at $2.45 \mathrm{GHz}$ respectively.

Table 2: Simulated results for correlation coefficient, TARC and capacity loss at $2.45 \mathrm{GHz}$.

\begin{tabular}{|c|c|c|}
\hline MIMO characteristic & $\begin{array}{c}\text { Microstrip } \\
\text { without EBG }\end{array}$ & $\begin{array}{c}\text { Microstrip with } \\
\text { EBG }\end{array}$ \\
\hline $\begin{array}{c}\text { Correlation } \\
\text { Coefficients }\end{array}$ & 0.08 & 0.02 \\
\hline TARC (dB) & -13.28 & -18.83 \\
\hline $\begin{array}{c}\text { Capacity loss } \\
\text { (bit/s/Hz) }\end{array}$ & 2.011 & 1.752 \\
\hline $\begin{array}{c}\text { Channel Capacity } \\
\text { (bits/s/Hz) }\end{array}$ & 5.768 & 5.589 \\
\hline
\end{tabular}

\section{Conclusion}

Two-element microstrip MIMO antennas covering $2.45 \mathrm{GHz}$ was presented. The EBG structures was applied to reduce the mutual coupling affects. The result shows that an improvement on mutual coupling was achieved when the EBG structures was employed. Further, the MIMO antenna performances also been analyzed. It can be concluded, that the proposed antenna is an ideal option for WLAN applications. 


\section{References}

[1] G. J. Foschini and M. J. Gans, "On limits of wireless communications in a fading environment when using multiple antennas," Wireless personal communications, vol. 6, pp. 311-335, 1998.

[2] J. Thaysen and K. B. Jakobsen, "Design considerations for low antenna correlation and mutual coupling reduction in multi antenna terminals," European transactions on telecommunications, vol. 18, pp. 319-326, 2007.

[3] S. Zhang, B. K. Lau, Y. Tan, Z. Ying, and S. He, "Mutual coupling reduction of two PIFAs with a T-shape slot impedance transformer for MIMO mobile terminals," Antennas and Propagation, IEEE Transactions on, vol. 60, pp. 1521-1531, 2012.

[4] H. S. Singh, B. Meruva, G. K. Pandey, P. K. Bharti, and M. K. Meshram, "Low Mutual Coupling Between Mimo Antennas By Using Two Folded Shorting Strips," Progress In Electromagnetics Research B, vol. 53, 2013.

[5] J.-N. Hwang and S.-J. Chung, "Isolation Enhancement Between Two Packed Antennas With Coupling Element," Antennas and Wireless Propagation Letters, IEEE, vol. 10, pp. 12631266, 2011.

[6] W. Marzudi, Z. Abidin, S. Muji, M. Yue, and R. A. Abd-Alhameed, "Minimization of Mutual Coupling Using Neutralization Line Technique for $2.4 \mathrm{GHz}$ Wireless Applications," International Journal of Digital Information and Wireless Communications (IJDIWC), vol. 4, pp. 26-32, 2014.

[7] O. Quevedo-Teruel, L. Inclan-Sanchez, and E. Rajo-Iglesias, "Soft surfaces for reducing mutual coupling between loaded pifa antennas," Antennas and Wireless Propagation Letters, IEEE, vol. 9, pp. 91-94, 2010.

[8] J.-F. Li, Q.-X. Chu, and T.-G. Huang, "A compact wideband MIMO antenna with two novel bent slits," Antennas and Propagation, IEEE Transactions on, vol. 60, pp. 482-489, 2012.

[9] K. M. Prasanna and S. Behera, "A Hexagonal MIMO Antenna System With Defected Ground Structure to Enhance Bandwidth and Isolation," 2013.

[10] P. Sharmaa and T. Khanb, "A Compact MIMO Antenna with DGS Structure," 2013.

[11] J. Zhu and G. V. Eleftheriades, "A simple approach for reducing mutual coupling in two closely spaced metamaterial-inspired monopole antennas," Antennas and Wireless Propagation Letters, IEEE, vol. 9, pp. 379-382, 2010.

[12] M. T. I. a. M. S. Alam, "Compact EBG Structure For Alleviating Mutual Coupling Between Patch Antenna Array Elements," Progress In Electromagnetics Research, vol. vol. 137, 2013.

[13] Z. Abidin, Y. Ma, R. Abd-Alhameed, K. Ramli, D. Zhou, M. Bin-Melha, et al., "Design of 2 x 2 U-shape MIMO slot antennas with EBG material for mobile handset applications," in Progress In Electromagnetics Research Symposium Marrakesh, 2011.

[14] L. Xiong and P. Gao, "Compact Dual-Band Printed Diversity Antenna For Wimax/Wlan Applications," Progress In Electromagnetics Research C, vol. 32, 2012. 